\title{
Frequency Security Constrained Energy Management in an Isolated Power System
}

\author{
UMER AKRAM ${ }^{1}$, MITHULANANTHAN NADARAJAH ${ }^{1}$, RAKIBUZZAMAN SHAH ${ }^{2}$, \\ SAIFULLAH SHAFIQ ${ }^{3}$ \\ ${ }^{1}$ School of IT and Electrical Engineering, The University of Queensland, Australia \\ ${ }^{2}$ School of Science Engineering and Information Technology, Federation University, Australia \\ ${ }^{3}$ Electrical Engineering Department, Prince Mohammad Bin Fahd University, Saudi Arabia
}

\begin{abstract}
Short-term frequency instability is one of the major challenges that arise due to large-scale penetration of converter interfaced renewable energy sources (RESs) in isolated power systems. The short-term frequency instability is associated with high values of rate of change of frequency (RoCoF) and larger frequency excursions. In this paper, a frequency constrained energy management algorithm is proposed. The proposed algorithm manages the power output of RESs, energy storage system, and electric vehicles (EVs) in such a way that the system keeps nonsynchronous power reserve for providing virtual inertia support to avoid high values of RoCoF and frequency excursions. The non-synchronous power reserve is readily available and when deployed can limit the RoCoF as per the required standard. The proposed management algorithm selects the non-synchronous power reserve from different resources, i.e., RES (solar PV, wind turbine), energy storage, and EV, depending on the availability and system loading conditions. Simulation results show the effectiveness of the proposed algorithm.
\end{abstract}

Key-Words: - Energy storage, electric vehicle, inertial response, renewable energy, RoCoF Received: May 2, 2020 Revised: September 23, 2020. Accepted: September 30, 2020.

Published: October 8, 2020.

\section{Introduction}

Conventional power systems are going through an evolution process where outdated generators are being replaced by renewable energy sources (RESs) [1]. In addition, the nature of load is changed due to the introduction of vehicle-to-grid (V2G) support services provided by electric vehicles (EVs) [2] This rapid transition in generation and load is influenced by global warming, energy security, and sustainability [3]. The large-scale penetration of converter interfaced renewable generations and loads alters the system dynamics which arises power system stability challenges.

Frequency instability is one of the major challenges associated with the large-scale integration of RESs in power systems [1]. In islanded systems, frequency stability is concerned for large disturbance resulting in larger frequency nadir and high rate of change of frequency (RoCoF) [4]. Many system elements and generators are highly sensitive to high RoCoF. It is difficult for gas, steam, and hydro turbines to remain in synchronism with other generators when the RoCoF is above $2 \mathrm{~Hz} / \mathrm{s}$ [5]. Phase-locked loop (PLL) fails to follow the voltage phase angle and grid frequency during the events of sudden frequency excursions [6]. The under-frequency load shedding (UFLS) relay may not operate instantly to avoid large frequency variations when RoCoF is over $3 \mathrm{~Hz} / \mathrm{s}$ [5]. Thus, keeping RoCoF within the permissible limits can ensure avoidance of short-term frequency instability.

The introduction of converter interfaced inertialess generation technologies jeopardizes the frequency stability. However, the advancement in power electronics enables the converter interfaced technologies to provide frequency regulation when deployed with proper control. Deloaded operation, over-speed control, and inertia emulation are the three modes that can be used by wind turbine (WT) to provide virtual inertia support (VIS) [7]. The WT having inertia constant more than $3.6 \mathrm{~s}$ can provide 0.1 p.u. (on wind turbine base) extra power for $10 \mathrm{~s}$ provided that the wind speed is more than $6.5 \mathrm{~m} / \mathrm{s}$ [8]. Therefore, with inertia emulation control the WT can provide the VIS [9]. In deloaded operation mode, the WT is operated at lower than the maximum power point. The WT increases the power 
output in case of contingency to provide frequency regulation [10]. Similarly, PV generation can also be operated in deloaded mode to provide frequency regulation services [11]. The EV can also provide frequency regulation using $\mathrm{V} 2 \mathrm{G}$ phenomenon [12]. In [13], an adaptive frequency droop control is proposed to provide the frequency regulation and to maintain the state-of-charge (SoC) level of EV battery at the desired level. An LQR-PID controller is proposed in [14] for EV to provide frequency regulation in two area power system. It is important to note that the response of RES and EV involve stochastic phenomenon. For example, in case of RES the power output depends on time of day and weather conditions which are uncontrollable. Similarly, in case of EV the V2G response depends on customer willingness, making it less controllable. Therefore, it is possible that at the time when VIS is required these resources provide zero output.

Unlike EV and RES, the response from energy storage system (ESS) can be better controlled as it does not involve stochastic phenomenon. In [15], a coordinated control strategy is proposed to energy storage and WT to provide VIS in isolated power systems. In [16], a derivative control is designed for energy storage to provide VIS. In addition to single ESS technologies, hybrid energy storages are also viable for frequency regulation. In [17], batterysupercapacitor hybrid storage is used to provide frequency regulation. The battery storage is deployed to provide primary frequency regulation, while supercapacitor is deployed to provide inertial support. In [18], superconducting magnetic energy storage is deployed in two area power system to provide frequency regulation.

In this paper, a frequency stability constrained energy management algorithm is proposed for an isolated power system. The power system deploys conventional generation, PV, WT, EV, and ESS. The proposed algorithm manages the power output of PV, WT, ESS, and EV while maintaining a noninertial power reserve in the system which can be deployed immediately in event of contingency. The synthetic inertial power reserve ensures the avoidance of short-term frequency instability in event of credible contingency. The proposed algorithm is tested for different operation conditions. Simulation results prove the effectiveness of the proposed algorithm.

\section{Proposed Methodology}

The block diagram of the power system used in this study is given in Fig. 1. The system employs conventional generation, comprised of hydro and thermal power plants, and RESs. The RESs employ

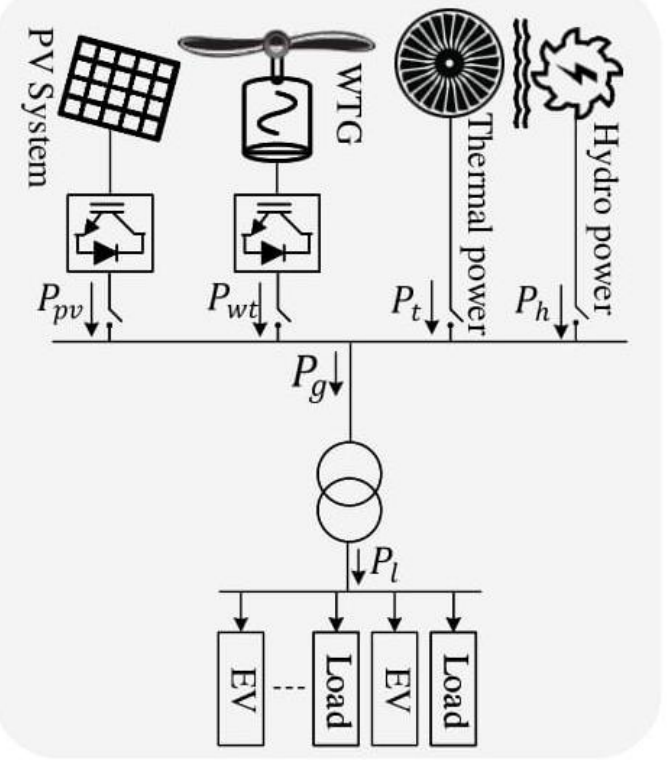

Fig. 1: An isolated power system.

both PV and WT generation systems. The power output of a WT can be estimated as [3].

$$
P_{w t}(v)=\left\{\begin{array}{cl}
0 & , v<v_{c i} \\
P_{w}^{r} \cdot \frac{v-v_{c i}}{v_{r}-v_{c i}} & , \quad v_{c i} \leq v<v_{r} \\
P_{w}^{r} & , \quad v_{r} \leq v<v_{c o} \\
0 & , v \geq v_{c o}
\end{array}\right.
$$

In (1), $P_{w}^{r}$ is the rated power of WT, $P_{w t}$ is the output power of WT, and $v_{r}, v_{c i}$, and $v_{c o}$ are rated, cut-in, and cut-out speeds respectively. In (1), $v$ is a function of time and thus $P_{w t}(v)$ is also a function of time. The power output of PV plant depends on solar irradiation, atmospheric temperature, efficiency, and area of the PV array. The output power of a PV system is estimated using (2) [3].

$$
P_{p v}(t)=\eta_{p v} A I(t)\left(1-0.005\left(T_{o}(t)-25\right)\right)
$$

In (2), $I$ is the solar irradiation, $\eta_{p v}$ is the efficiency, $A$ is the area, and $T_{o}$ is the atmospheric temperature. The total power generated is $P_{g}(t)=$ $P_{p v}(t)+P_{w t}(t)+P_{t}(t)+P_{h}(t) . \quad P_{g}$ is the total power generated, $P_{t}$ is the output power of thermal power plant, and $P_{h}$ is the power output of hydro power plant.

In modern power systems, there are two types of loads; controllable and uncontrollable [19]. In this paper, EVs are considered as controllable loads. The total controllable load at any time depends on the number of EVs connected to the system.

$$
P_{e v}(t)=\left\{\begin{array}{cc}
\sum_{i=1}^{n_{e v}^{t}} P_{e v}^{r}, & \forall n_{e v}^{t}>0 \\
0, & \text { else }
\end{array}\right.
$$


In (3), $P_{e v}$ is the total EV load, ntev is the number of EVs connected to system at time $t, P_{e v}^{r}$ is the rated power of EV. The total load on the system is $P_{l}(t)=P_{e v}(t)+P_{u c}(t)$, where, $P_{u c}$ is the uncontrollable load.

The load and power output of RES is stochastic and continuously varies over time. The difference in demand and generation causes variation in system frequency. The frequency response of small power system can be approximated using the following equation.

$$
\frac{2 H_{s y s}}{f} \frac{d f}{d t}=\frac{P_{g}-P_{l}}{S_{s y s}}
$$

In (4), $H_{\text {sys }}$ is the equivalent inertia of the system, $S_{s y s}$ is the MVA rating of the system, and $f$ is the frequency. The equivalent inertia of a system with $n_{g}$ generators can be estimated using the following equation.

$$
H_{\text {sys }}=\frac{\sum_{i=1}^{n_{g}} H_{i} S_{i}}{S_{\text {sys }}}
$$

In (5), $H_{i}$ and $S_{i}$ are the inertia and MVA rating of the $i_{t h}$ generator. In (4), $d f / d t$ is RoCoF, which is influenced by inertia and the difference between generation and demand. The inertia of the system depends on the number of online generators which can be assumed constant in this work. The difference between generation and demand can be controlled by keeping a power reserve online in the system and by dispatching it when needed. Therefore, to limit the RoCoF to a desired value an

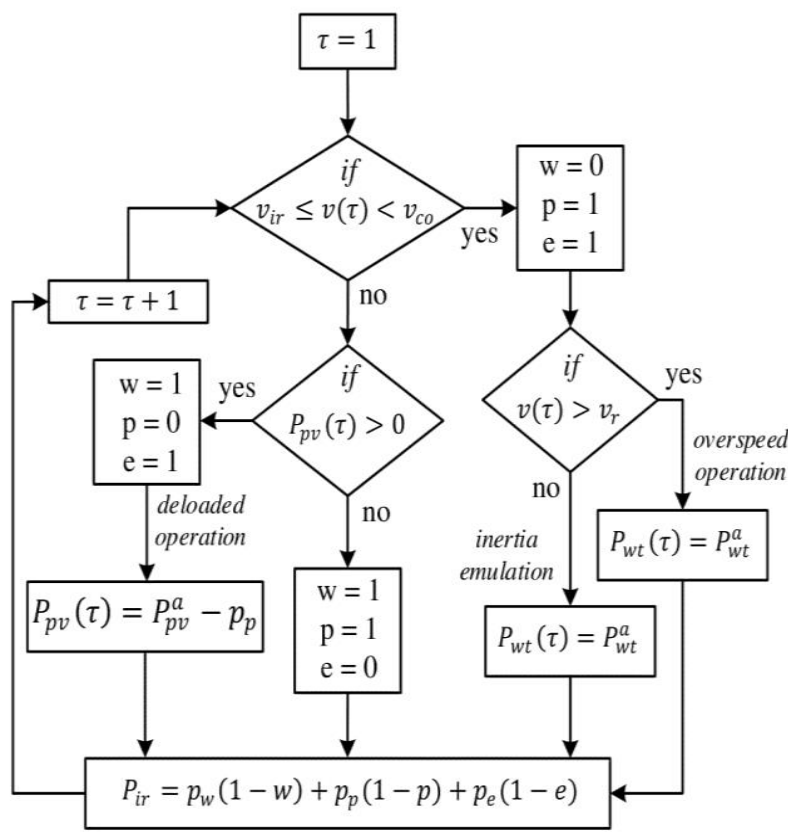

Fig. 2: Resources management algorithm. online non-synchronous inertia reserve can be procured. The swing equation of the system can be modified as following.

$$
\frac{2 H_{s y s}}{f} \frac{d f}{d t}=\frac{P_{g}-P_{l}+P_{i r}}{S_{s y s}}
$$

In (6), $P_{i r}$ is the power output of inertial reserve. The inertial reserve is deployed only during the credible contingency event. The test system considered in this study employs PV, WT, and EVs, and these resources can also be used as inertial reserve. Inertia emulation, over-speeding, and deloaded operation are the means by which WT can provide inertial support. The PV can also provide inertial support in deloaded mode operation. Similarly, EVs can be used for the VIS by controlling their charging rate. The algorithm shown in Fig. 2 is developed that selects the reserve for inertial support based on the availability of PV, WT, and EVs. The algorithm also selects the appropriate operation mode for the selected inertial reserve. In Fig. 2, $w, p, e$ are the decision variables that can take value 0 or 1 . In the algorithm, 0 means source is selected for inertial support, while 1 means source is not selected for inertial support. The $\tau$ is the step size, i.e., 15 minutes. It is assumed that the power output of RES remains constant throughout the time step $(\tau)$. In the Fig. 2, pw; pp, and pe are the power outputs of WT, PV, and EVs when selected for providing inertial response.

Table 1: Parameters of CPS

\begin{tabular}{lcccc}
\hline $\begin{array}{l}\text { Power } \\
\text { generation } \\
\text { unit }\end{array}$ & $\begin{array}{c}\text { Power } \\
\text { rating } \\
(\text { MVA) }\end{array}$ & $\begin{array}{c}\text { Active } \\
\text { power } \\
(\mathrm{MW})\end{array}$ & $\begin{array}{c}\text { Inertia } \\
\text { constant } \\
\text { (s) }\end{array}$ & $\begin{array}{c}\text { Number } \\
\text { of units } \\
(-)\end{array}$ \\
\hline G1 & 750 & 600 & 10.0128 & $3 / 2^{*}$ \\
\hline G2 & 640 & 400 & 8.3213 & 4 \\
\hline G3 & 384 & 250 & 6.9344 & 2 \\
\hline G4 & 474 & 300 & 6.6722 & 3 \\
\hline RES & 0 & 0 & 0 & - \\
\hline Total & 2248 & 1550 & 8.3010 & - \\
\hline Total* & 1998 & - & $8.0868^{*}$ & - \\
\hline
\end{tabular}

* The equivalent values after the loss of one unit of G1

\section{Simulation Results and Discussions}

A generic 12-bus system is used to study the effectiveness of the proposed methodology. The system without the RES is termed as conventional power system (CPS) and generator data is given in Table 1. The equivalent inertia given in Table 1 is estimated using the expression given in (5). The $60 \%$ RES penetration is introduced by replacing the conventional generators by PV and WT. The system with $60 \%$ penetration level of RES is referred here as a hybrid power system (HPS). The parameters of 
Table 2: Parameters of HPS

\begin{tabular}{lcccc}
\hline $\begin{array}{l}\text { Power } \\
\text { generation } \\
\text { unit }\end{array}$ & $\begin{array}{c}\text { Power } \\
\text { rating } \\
(\mathrm{MVA})\end{array}$ & $\begin{array}{c}\text { Active } \\
\text { power } \\
(\mathrm{MW})\end{array}$ & $\begin{array}{c}\text { Inertia } \\
\text { constant } \\
(\mathrm{s})\end{array}$ & $\begin{array}{c}\text { Number } \\
\text { of units } \\
(-)\end{array}$ \\
\hline G1 & 750 & 600 & 10.0128 & $3 / 2^{*}$ \\
\hline G4 & 158 & 100 & 6.6722 & 1 \\
\hline RES & 1340 & 850 & 0 & - \\
\hline \hline Total & 2248 & 1550 & 3.8095 & - \\
\hline Total* & 1998 & - & $3.033^{*}$ & - \\
\hline
\end{tabular}

* The equivalent values after the loss of one unit of G1

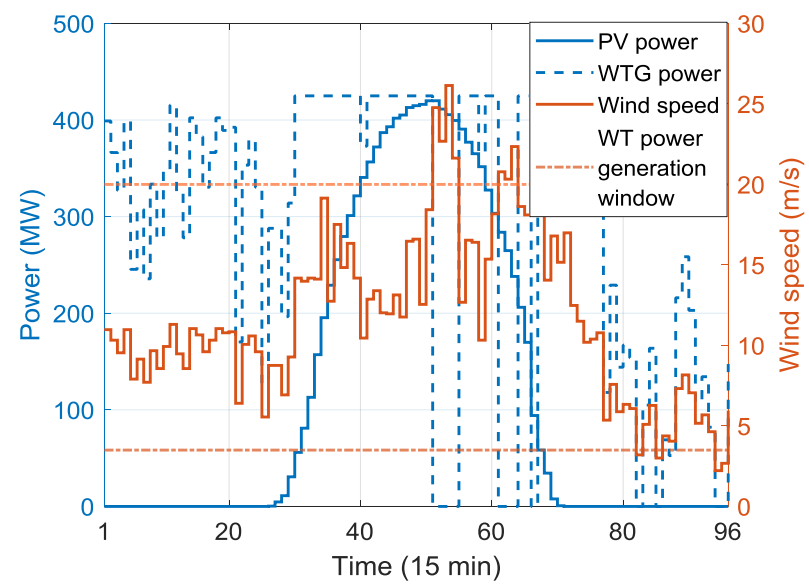

Fig. 3: Variations in wind speed, power output of WT, and power output of PV.

HPS are also given in Table 2. It can be seen from Table 1 that the system equivalent inertia is decreased with the replacement of conventional generation plants with RESs. In HPS, the total capacity of RES is comprised of 50\% from PV generation and 50\% from WT generation.

The power output of PV generation system, WT generation system, and wind speed for one day is shown in Fig. 3. The figure has two y-axis. The left $\mathrm{y}$-axis shows the variations in power output of PV and WT with the time given on $\mathrm{x}$-axis. The right $\mathrm{y}$ axis shows the variations in wind speed with the time given on x-axis. It can be observed that PV generates during the daytime only with the maximum power around mid-day. The power output of WT varies with the wind speed. The WT generates power only when the wind speed is within the WT power generation window.

The largest generator in HPS is G1 (there are three units of G1 in total) having capacity of 250 MVA/200 MW. The outage of G1 is considered as credible contingency. The power system frequency security requires the frequency nadir and RoCoF should remain within the acceptable limits after the credible contingency. The variations in system frequency and RoCoF of HPS after the credible con-

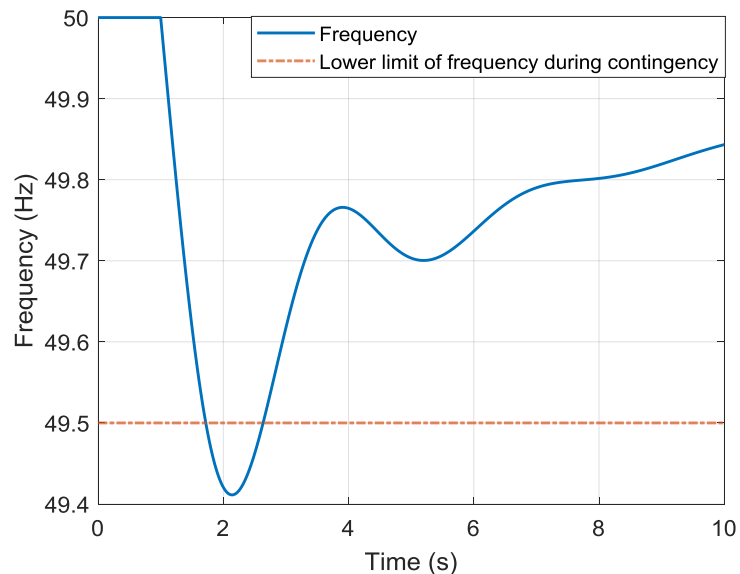

Fig. 4: Variations in system frequency.

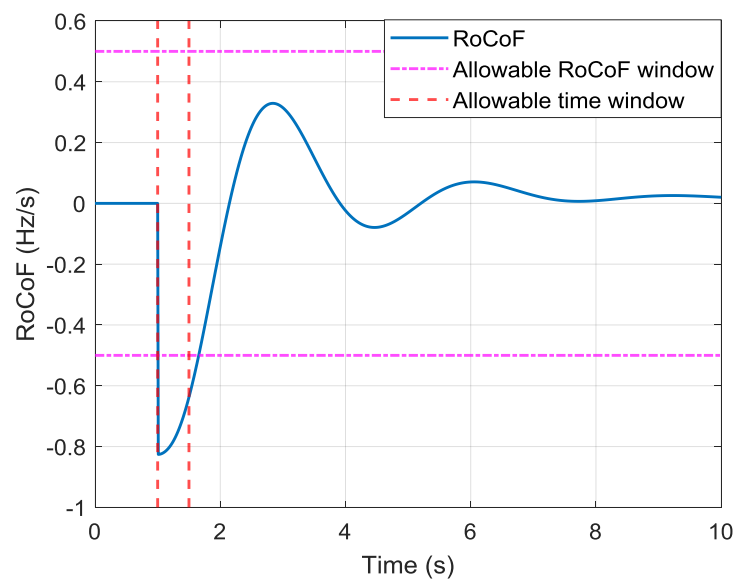

Fig. 5: Variations in RoCoF without inertial support. tingency are shown in Figs. 4 and 5, respectively. It can be observed that the frequency falls outside the allowable window. This can result in activation of under frequency load shedding. The RoCoF also remains higher than the allowable value, which can result in generation tripping. Thus, it is vital to have VIS for the secure operation.

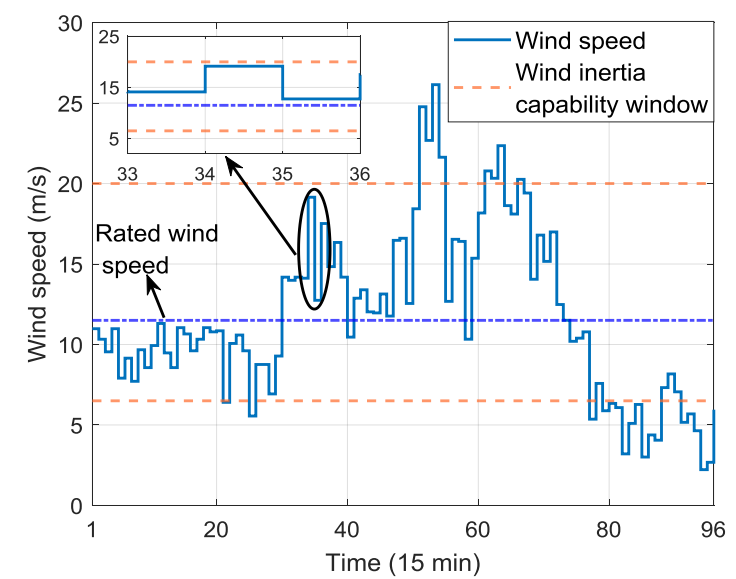

Fig. 6: Variations in wind speed during interval 34.

\subsection{Case 1: WT Providing Inertial Support}

The variations in wind speed are shown in Fig. 6. It can be noticed that during interval 34 wind speed is 


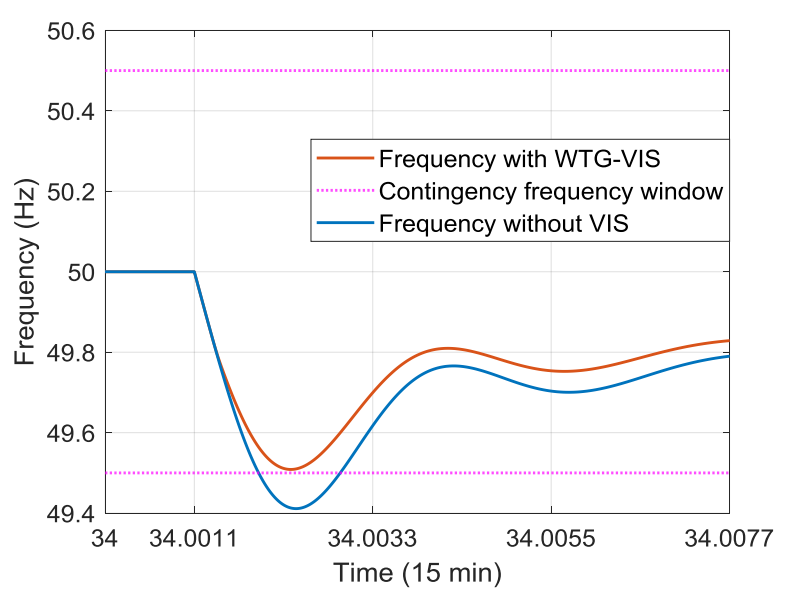

Fig. 7: Variations in frequency during interval 34.

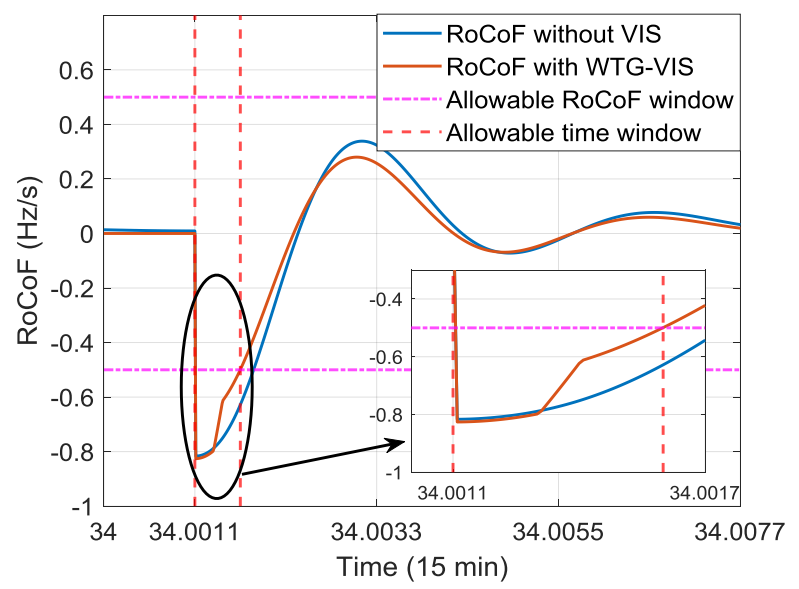

Fig. 8: Variations in RoCoF during interval 34.

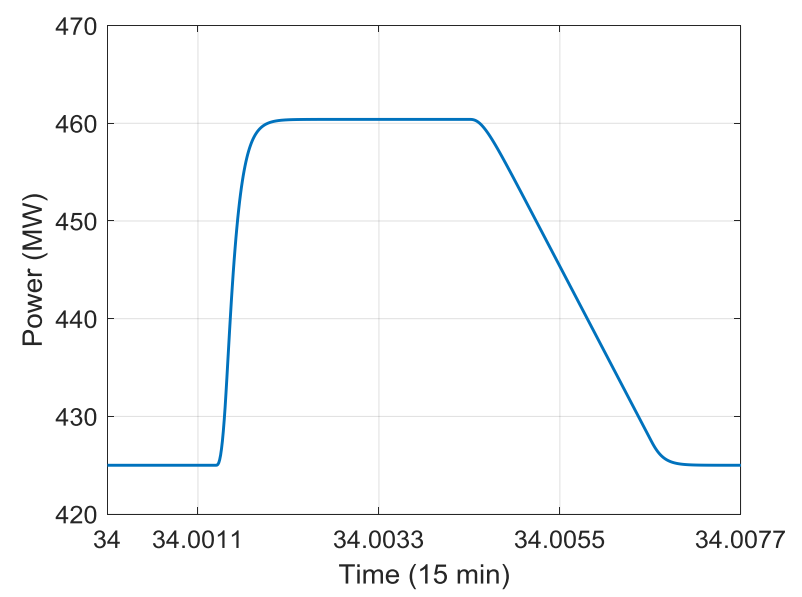

Fig. 9: Variations in WT power output.

higher than the rated speed. Therefore, the methodology developed in Section 2 selects WT for providing inertial support. The decision variables are selected as $\{w=0, p=1, e=1\}$. The overspeeding operation mode is selected for providing extra power. It is important to note that each interval is 15 minutes long. A major disturbance is applied at the first second of interval 34. The variations in frequency with and without the inertial support are shown in Fig. 7. It can be observed that the frequency with inertial support is constrained within the acceptable limits. The variations in RoCoF are given in Fig. 8. It can be observed that the WT limits the RoCoF to acceptable value within the $500 \mathrm{~ms}$. While RoCoF of the system without the WT falls outside the maximum allowable value for more than $500 \mathrm{~ms}$. The variations in power output of WT is given in Fig. 9. The WT injects the available power in the system before the occurrence of event. The WT increases the power output using overspeeding control. After providing the service the WT returns to normal operation mode

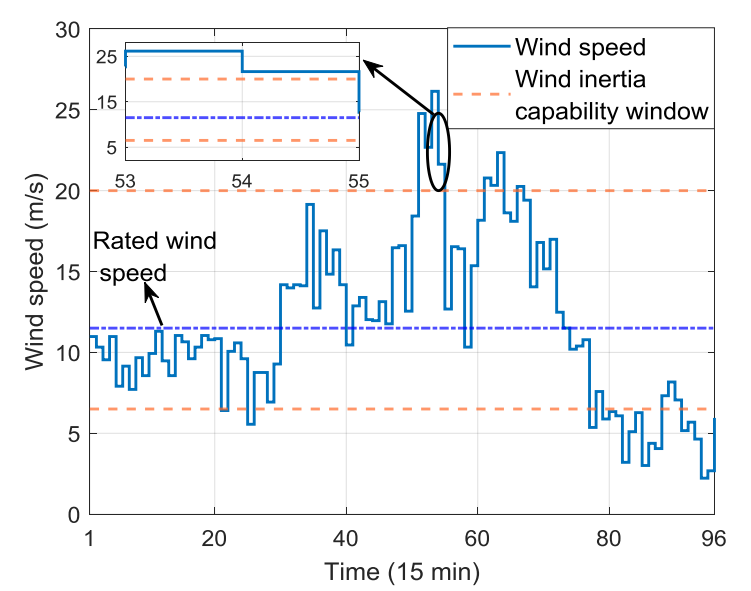

Fig. 10: Variations in wind speed during interval 54.

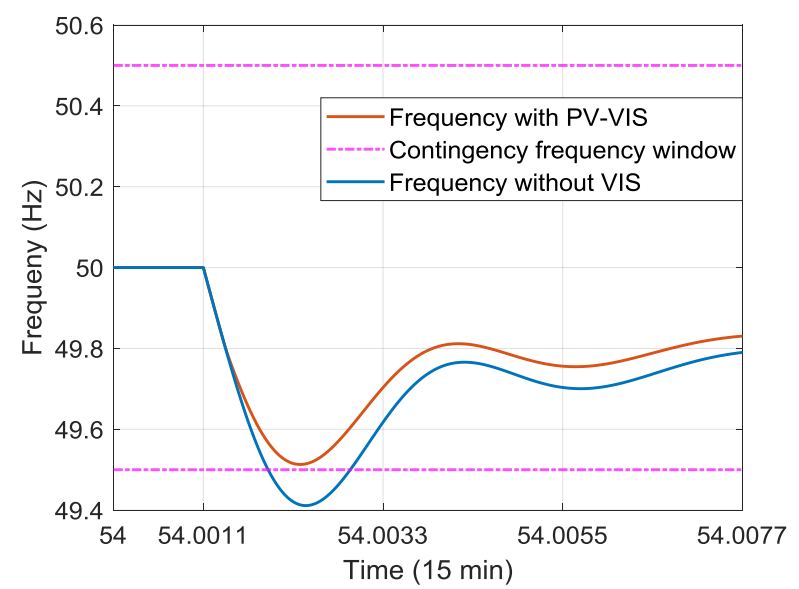

Fig. 11: Variations in frequency during interval 54.

\subsection{Case 2: PV Providing Inertial Support}

In this case, PV system provides the inertial support. The variations in wind speed are shown in Fig. 10. The wind speed during the interval number 54 is more than the cut-out speed. Therefore, WT generates no power output. It is evident from the Fig. 3 that during the interval number 54 available power output of PV system is around $400 \mathrm{MW}$. Thus, the proposed algorithm selects PV system for 


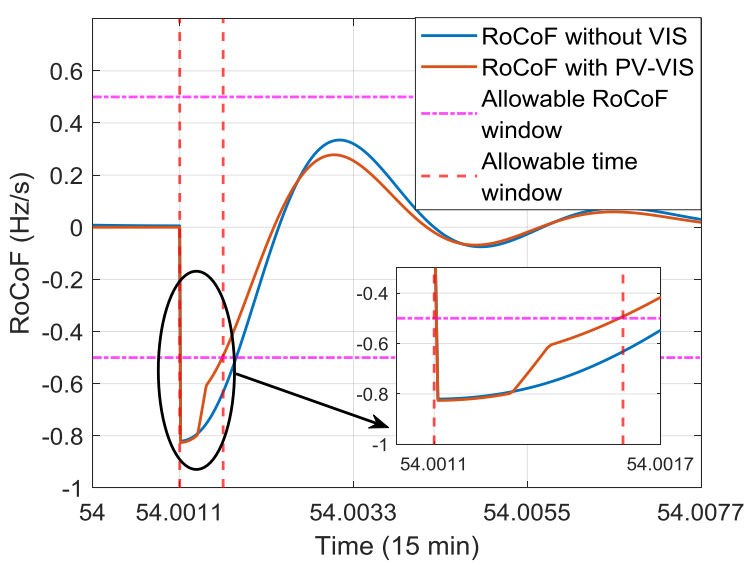

Fig. 12: Variations in RoCoF during interval 54.

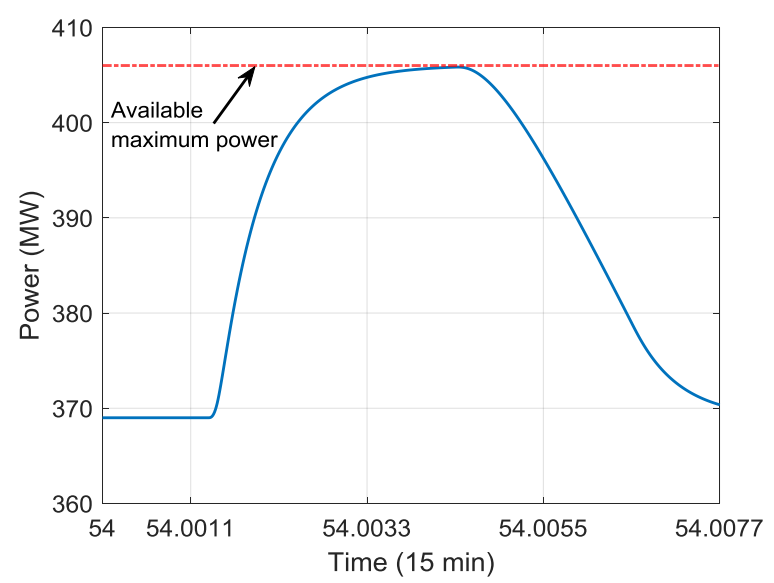

Fig. 13: Variations in PV power output.

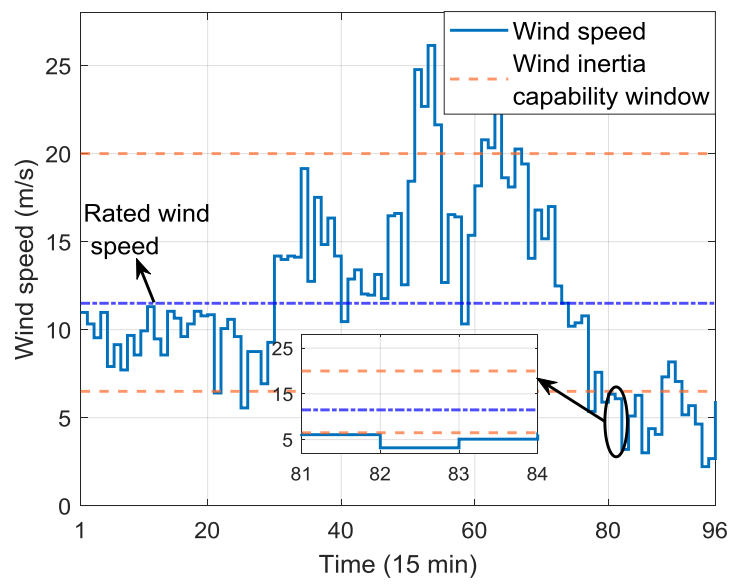

Fig. 14: Variations in wind speed during interval 82.

inertial support during this interval. As discussed earlier, the PV system can only provide inertial support when operated in deloaded mode. Hence, the proposed algorithm selects the deloaded operation mode of PV system.

The variations in system frequency and RoCoF in response to credible contingency are shown in Fig. 11 and 12, respectively. It can be observed that both frequency and RoCoF are constrained within the acceptable limits. While both frequency and
RoCoF falls outside the minimum allowable values without the inertial support reserve. The variations in power output of PV system are shown in Fig. 13. It can be observed that PV system is operated in deloaded mode before the occurrence of event. The PV system increases power output to the full available power on the occurrence of the event to decrease the RoCoF and frequency nadir. After supplying the service the PV system is again operated in deloaded mode.

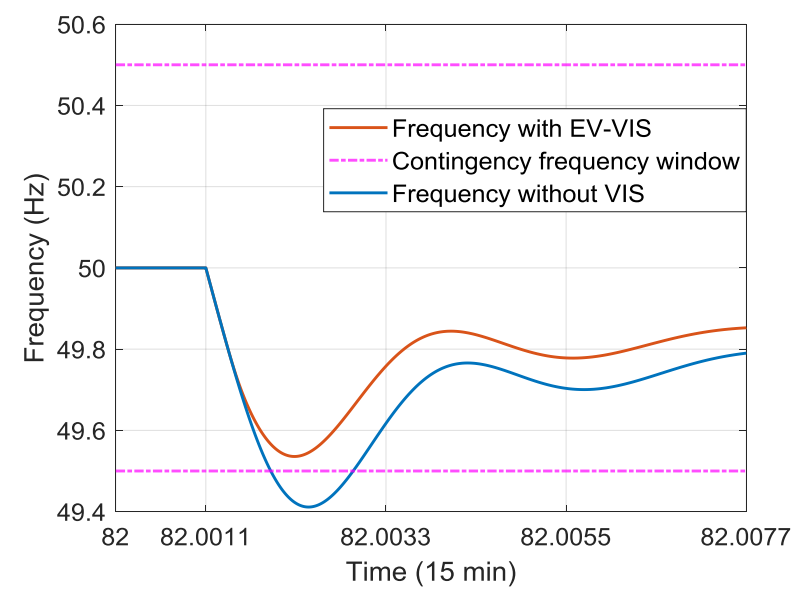

Fig. 15: Variations in frequency during interval 82.

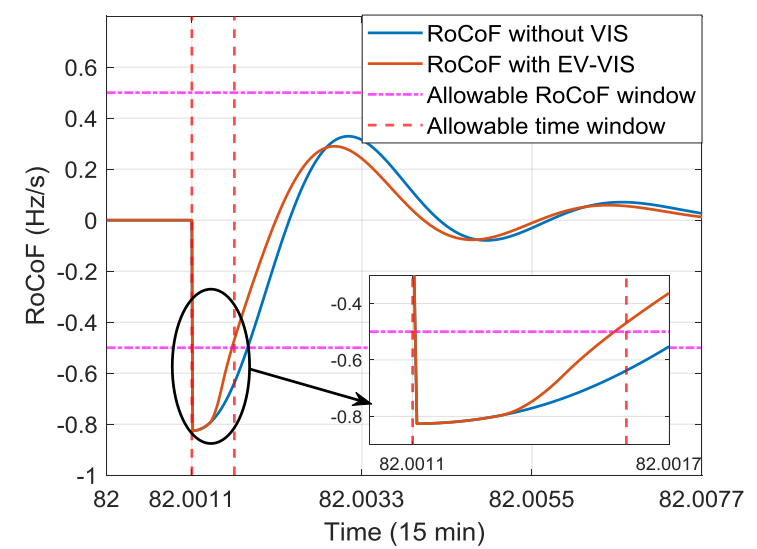

Fig. 16: Variations in RoCoF during interval 82.

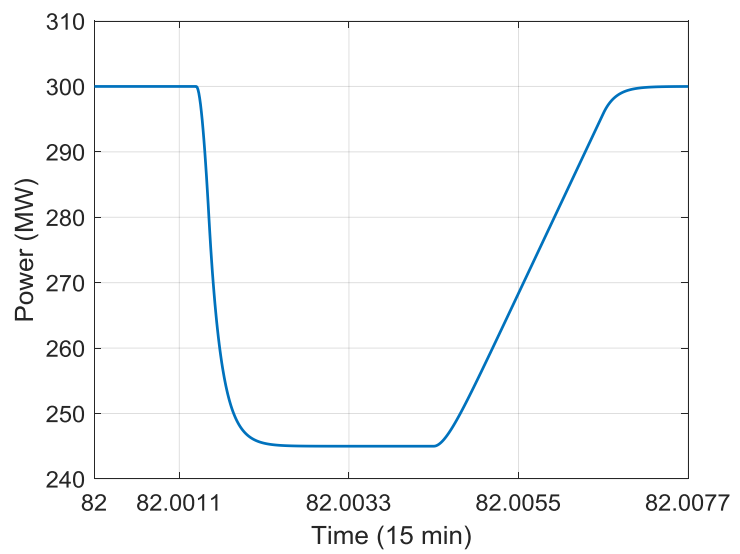

Fig. 17: Variations in EV charging power. 


\subsection{Case 3: EV Providing Inertial Support}

In this case, the EV are used to provide the inertial support. During the interval number 82 the wind speed is less than the cut-in speed as shown in Fig. 14. Therefore, WT provides zero power output. In addition, the PV system also generates zero output during this interval. The interval number 82 represents the half passed 8 at night. Most of the people are staying home at this time and put their EVs on charging. Thus, EVs can be used to provide inertial support during this interval.

A credible contingency is created in the system at first second of the interval number 82. The variations in system frequency and $\mathrm{RoCoF}$ are shown in Fig. 15 and 16, respectively. The inertial response from EVs successfully constraints both the frequency and the RoCoF within the allowable limits. The variations in charging power of EVs is shown in Fig. 17. The EVs are being charged at the rated charging capacity before the event. At the time of occurrence of the event, EVs decrease their charging rates temporarily to support the grid. After supplying the event the EVs again start charging at the rated charging capacity.

\section{Conclusion}

In this article, a frequency constrained energy management system is developed for an isolated power system with high penetration of renewable energy sources (RESs). The proposed methodology manages the power output of the available resources to limit the RoCoF and frequency nadir within the acceptable limits, in event of contingency. The proposed technique is applied to an isolated power system with $60 \%$ renewable penetration. It has been shown that the proposed energy management system effectively controls the power output of different resources and successfully limits the frequency deviations and RoCoF within the acceptable limits.

\section{References:}

[1] U. Akram, M. Nadarajah, R. Shah, and F. Milano, "A review on rapid responsive energy storage technologies for frequency regulation in modern power systems," Renewable and Sustainable Energy Reviews, vol. 120, p. 109626, 2020.

[2] S. Shafiq, U. B. Irshad, M. Al-Muhaini, S. Z. Djokic, and U. Akram, "Reliability evaluation of composite power systems: Evaluating the impact of full and plug-in hybrid electric vehicles," IEEE Access, pp. 114 305-114 314, 2020 .
[3] U. Akram, M. Khalid, and S. Shafiq, "Optimal sizing of a wind/solar/battery hybrid gridconnected microgrid system," IET Renewable Power Generation, vol. 12, no. 1, pp. 72-80, 2017.

[4] P. Kundur, J. Paserba, V. Ajjarapu, G. Andersson, A. Bose, C. Canizares, N. Hatziargyriou, D. Hill, A. Stankovic, C. Taylor et al., " Definition and classification of power system stability IEEE/CIGRE joint task force on stability terms and definitions," IEEE Transactions on Power Systems, vol. 19, no. 3, pp. 1387-1401, 2004.

[5] AEMO, "Fast frequency response in the NEM," Future power system security program, AEMO Information \& Support Hub, Tech. Rep., Australia, 2017.

[6] CIGRE working group B4.62, "Connection of wind farms to weak AC networks," 2016.

[7] M. Dreidy, H. Mokhlis, and S. Mekhilef, "Inertia response and frequency control techniques for renewable energy sources: A review," Renewable and Sustainable Energy Reviews, vol. 69, pp. 144-155, 2017.

[8] N. R. Ullah, T. Thiringer, and D. Karlsson, "Temporary primary frequency control support by variable speed wind turbines potential and applications," IEEE Transactions on Power Systems, vol. 23, no. 2, pp. 601-612, 2008.

[9] R. Azizipanah-Abarghooee, M. Malekpour, T. Dragicevic, F. Blaabjerg, and V. Terzija, "A linear inertial response emulation for variable speed wind turbines," IEEE Transactions on Power Systems, vol. 35, no. 2, pp. 1198-1208, 2019.

[10] K. Vidyanandan and N. Senroy, "Primary frequency regulation by deloaded wind turbines using variable droop," IEEE Transactions on Power Systems, vol. 28, no. 2, pp. 837-846, 2012.

[11] P. Zarina, S. Mishra, and P. Sekhar, "Exploring frequency control capability of a PV system in a hybrid PV-rotating machinewithout storage system," International Journal of Electrical Power \& Energy Systems, vol. 60, pp. 258-267, 2014.

[12] S. Han, S. Han, and K. Sezaki, "Development of an optimal vehicle-togrid aggregator for frequency regulation," IEEE Transactions on Smart Grid, vol. 1, no. 1, pp. 65-72, 2010.

[13] H. Liu, Z. Hu, Y. Song, and J. Lin, "Decentralized vehicle-to-grid control for primary frequency regulation considering charging demands," IEEE Transactions on 
Power Systems, vol. 28, no. 3, pp. 3480-3489, 2013.

[14] S. K. Das, M. Rahman, S. K. Paul, M. Armin, P. N. Roy, and N. Paul, "High-performance robust controller design of plug-in hybrid electric vehicle for frequency regulation of smart grid using linear matrix inequality approach," IEEE Access, vol. 7, pp. 116911116924, 2019.

[15] U. Akram, M. Nadarajah, M. Q. RAZA, R. Shah, and F. Milano, "Rocof restrictive planning framework and wind speed forecast informed operation strategy of energy storage system," IEEE Transactions on Power Systems, 2020.

[16] V. Knap, S. K. Chaudhary, D.-I. Stroe, M. Swierczynski, B.-I. Craciun, and R. Teodorescu, "Sizing of an energy storage system for grid inertial response and primary frequency reserve," IEEE Transactions on Power Systems, vol. 31, no. 5, pp. 3447-3456, 2015.

[17] U. Akram, R. Shah, and N. Mithulananthan, "Hybrid energy stoarage system for frequency regulation in microgrids with source and load uncertainties," IET Generation, Transmission \& Distribution, vol. 13, no. 22, pp. 5048-5057, 2019.

[18] M. Elsisi, M. Soliman, M. Aboelela, and W. Mansour, "Optimal design of model predictive control with superconducting magnetic energy storage for load frequency control of nonlinear hydrothermal power system using bat inspired algorithm," Journal of Energy Storage, vol. 12, pp. 311-318, 2017.

[19] M. Babaei, E. Azizi, M. T. Beheshti, and M. Hadian, "Data-driven load management of stand-alone residential buildings including renewable resources, energy storage system, and electric vehicle," Journal of Energy Storage, vol. 28, p. 101221, 2020.

\section{Contribution of individual authors to the creation of a scientific article (ghostwriting policy)}

Author Contributions: Please, indicate the role and the contribution of each author:

Example

John Smith, Donald Smith carried out the simulation and the optimization.

George Smith has implemented the Algorithm 1.1 and 1.2 in $\mathrm{C}++$.
Maria Ivanova has organized and executed the experiments of Section 4.

George Nikolov was responsible for the Statistics.

Follow: www.wseas.org/multimedia/contributor-

role-instruction.pdf

\section{Sources of funding for research presented in a scientific article or scientific article itself \\ Report potential sources of funding if there is any}

\section{Creative Commons Attribution License 4.0 (Attribution 4.0 International, CC BY 4.0)}

This article is published under the terms of the Creative Commons Attribution License 4.0

https://creativecommons.org/licenses/by/4.0/deed.en_US 